\title{
RANCANG BANGUN MEDIA PEMBELAJARAN AVIONIC - ADF (AUTOMATIC DIRECTION FINDING SYSTEM) BERBASIS MULTIMEDIA ANIMASI PADA ATKP MEDAN
}

\author{
Suyatmo $^{1}$, Hadi Prayitno ${ }^{1}$, Ulfa Hasnita ${ }^{1}$, Iswandi Idris ${ }^{2 *}$, Rizaldy Khair ${ }^{2}$ \\ ${ }^{1}$ Politeknik Penerbangan Medan \\ J1. Penerbangan No. 85, Sempakata, Kec. Medan Selayang, Medan \\ ${ }^{2}$ Politeknik LP3I Medan \\ J1. Sei Serayu No. 48 D, Medan \\ ha pray@yahoo.co.id', iswandi.idris@plm.ac.id²*, rizaldyk.lp3iegmail.com²
}

\begin{abstract}
The importance of learning media is utilized by ATKP Medan as an opportunity to continue to improve the quality of learning. However, the most common problem in avionic learning is the limited resources available. This is because to access Avionic learning, cadets can only access it from LAB CBT. This is because Avionic software is only installed inside the lab and cannot be learned from outside the lab. The purpose of this research is to improve the learning process of Avionic - Automatic Direction Finding System digitally which is packaged in multimedia animation to make it easier for cadets to learn the Avionic Automatic Direction Finding System without having access in the laboratory. The method used in this study is to use the MDLC Multimedia Development Life Cycle method, namely the Concept, Design, Material Collecting, Manufacturing, Testing, Distribution methods. The learning media produced from this study are by displaying 5 types of display pages, namely Introduction, ADF Components, Sense Antennas, Antenna Components, and Direction Finding System.
\end{abstract}

Keywords - Learning Media, Avionic, ADF, ATKP Medan

\begin{abstract}
Pentingnya media pembelajaran dimanfaatkan oleh ATKP Medan sebagai kesempatan untuk terus meningkatkan mutu pembelajaran. Namun, permasalahan yang paling sering terjadi dalam pembelajaran avionic adalah adanya keterbatasan resource yang ada. Hal ini dikarenakan untuk mengakses pembelajaran Avionic para taruna hanya bisa mengaksesnya dari LAB CBT. Hal ini disebabkan software Avionic hanya terpasang didalam lab dan tidak bisa dipelajari dari luar lab. Tujuan dalam penelitian ini adalah meningkatkan proses pembelajaran Avionic - Automatic Direction Finding System secara digital yang dkemas dalam animasi multimedia untuk memudahkan para taruna untuk mempelajari Avionic Automatic Direction Finding System tanpa harus akses di laboratorium. Metode yang digunakan dalam penelitian ini adalah menggunakan Dengan menggunakan metode Multimedia Development Life Cycle MDLC yaitu metode Konsep (Concept), Perancangan (Desain), Pengumpulan Bahan (Material Collecting), Pembuatan (Assembly), Pengujian (Testing), Distribusi (Distribution). Media pembelajaran yang dihasilkan dari penelitian ini adalah dengan menampilkan 5 jenis halaman tampilan yaitu Introduction, Komponen ADF, Sense Antenna, Komponen Antena dan Direction Finding System.
\end{abstract}

Kata kunci - Media Pembelajaran, Avionic, ADF, ATKP Medan.

\section{PENDAHULUAN}

Video sebagai media pembelajaran sudah cukup marak digunakan dalam pembelajaran. Media video pembelajaran dapat digolongkan kedalam jenis media Audio Visual Aids (AVA) atau media yang dapat dilihat atau didengar.

Media Audio Motion Visual (Media Audio Visual Gerak) yakni media yang mempunyai suara, ada gerakan dan bentuk obyeknya dapat dilihat, media ini paling lengkap. Menurut Anissatul (2009) media video pembelajaran adalah media yang menyajikan audio dan visual yang berisi pesan-pesan pembelajaran baik yang berisi konsep, prinsip, prosedur, teori aplikasi pengetahuan untuk membantu pemahaman terhadap suatu materi pembelajaran. Mayer (2012:87) menjelaskan pula bahwa media pembelajaran berbasis gambar bergerak (animasi/video) dapat mendorong pemahaman peserta didik bila digunakan dengan cara yang konsisten dengan teori pembelajaran multimedia.

Rayandra Asyar (2011:8) bahwa media pembelajaran dapat dipahami sebagai segala sesuatu yang dapat menyampaikan atau menyalurkan pesan dari suatu seumber secara terencana, sehingga terjadi lingkungan belajar yang kondusif dimana penerimanya dapat melakukan proses belajar mengajar secara efisien dan efektif. Sehingga materi pembelajaran lebih cepat diterima siswa dengan utuh serta menarik minat siswa untuk belajar lebih lanjut. 
Niken dan Haryanto (2010:25) mengatakan bahwa multimedia interaktif adalah suatu multimedia yang dilengkapi dengan alat pengontrol yang dapat dioperasikan oleh pengguna sehingga pengguna dapat memilih apa yang dikehendakinya untuk proses selanjutnya. Niken dan haryanto (2010:11) mengemukakan bahwa multimedia merupakan perpaduan antara berbagai media (format file) yang berupa teks, gambar (vector atau bitmap), grafik, sound, animasi, video, interaksi, dan lainlain yang telah dikemas menjadi file digital (komputerisasi), digunakan untuk menyampaikan pesan kepada publik.

Niken dan Haryanto (2012:12) manfaat multi media yaitu: (1) Pengenalan teknologi informasi dan komunikasi kepada mahasiswa, (2) Memeberikan pengalaman baru dan menyenangkan baik bagi dosen itu sendiri maupun mahasiswa, (3) Mengejar ketertinggalan pengetahuan tentang Iptek di bidang pendidikan, (4) Pemanfaatan multimedia dapat membangkitkan motivasi belajar para pembelajar, (5) Multimedia dapat digunakan untuk membantu pembelajar membentuk model mental yang akan memudahkannya memahami suatu konsep, (6) Mengikuti perkembangan Ipteks. Meningkatkan layanan yang ditawarkan kepada pelanggan internal dan eksternal [1], peningkatan penggunaan ICT [2]

Avionic merupakan peralatan elektronik penerbangan yang mencakup seluruh sistem elektronik yang dirancang untuk digunakan di pesawat terbang. Sistem utamanya meliputi sistem komunikasi, navigasi dan indikator serta manajemen dari keseluruhan sistem. Avionik juga mencakup ratusan sistem yang berada di pesawat terbang dari yang paling sederhana seperti lampu pencari pada helikopter polisi sampai sistem yang kompleks seperti sistem taktikal pada pesawat peringatan dini. (wikipedia: 2019), selama ini pembelajaran avionic dilakukan di LAB CBT dengan aplikasi desktop yang sudah terinstal didalamnya yang langsung terkoneksi ke server di New York. Hal ini cukup menyulitkan para taruna dalam proses pembelajaran, cukup menyulitkan dalam mengulang pembelajaran karena satu satunya akses adalah akses kedalam LAB CBT, terutama untuk materi ADF (Automatic Direction Finding System). Untuk itu dibutuhkan suatu media pembelajaran dalam bentuk rancang bangun berbasis multimedia animasi.

Berdasarkan uraian permasalahan diatas, maka peneliti melakukan penelitian dengan judul "Bagaimana Rancang Bangun Media Pembelajaran Avionic - ADF (Automatic Direction Finding System) Berbasis Multimedia Animasi pada ATKP Medan".

Diharapkan dari rancangan ini adalah Produk video Avionic Automatic Direction Finding System dan modul media pembelajaran avionic Automatic Direction Finding System berbasis multimedia animasi dapat memberikan dampak positif dalam proses pembelajaran.

\section{A. Avionik}

Avionik berarti peralatan elektronik penerbangan yang mencakup seluruh sistem elektronik yang dirancang untuk digunakan di pesawat terbang. Sistem utamanya meliputi sistem komunikasi, navigasi dan indikator serta manajemen dari keseluruhan sistem. Avionik juga mencakup ratusan sistem yang berada di pesawat terbang dari yang paling sederhana seperti lampu pencari pada helikopter polisi sampai sistem yang kompleks seperti sistem taktikal pada pesawat peringatan dini [3]

\section{B. Radio Direction Finder (RDF)}

Radio Direction Finder (RDF) adalah alat untuk menemukan arah, atau bantalan, ke sumber radio. Tindakan pengukuran arah dikenal sebagai arah radio temuan atau kadang-kadang hanya menemukan arah (DF). Menggunakan dua atau lebih pengukuran dari lokasi yang berbeda, lokasi pemancar yang tidak diketahui dapat ditentukan bergantian, menggunakan dua atau lebih pengukuran pemancar diketahui, lokasi kendaraan dapat ditentukan. RDF banyak digunakan sebagai sistem navigasi radio, terutama dengan kapal dan pesawat [4].

\section{Automatic Direction Finder (ADF)}

Automatic direction finder (ADF) adalah suatu alat navigasi yang berfungsi sebagai petunjuk arah yang menunjukkan arah relatif pesawat terhadap titik tujuan di darat. ADF digunakan bersama dengan nondirectional beacon (NDB) yang berbasis ditanah, instrumen menampilkan jumlah derajat searah jarum jam dari hidung pesawat ke stasiun yang diterima. ADF memiliki keuntungan bila dibandingkan dengan alat navigasi VOR dalam hal penerimaan sinyalnya tidak terbatas pada line of sight. Sinyal ADF mengikuti kelengkungan bumi. Maksimum jarak tergantung pada kekuatan NDB.[5].

ADF (Automatic Directional Finder) menggunakan frequensi rendah sampai menengah, dari frequensi $190 \mathrm{Khz}$ sampai $1750 \mathrm{Khz}$, ADF dapat menerima dua sinyal radio, yaitu sinyal AM dan NDB (Non-Directional Beacon), pada saluran sinyal komersial disiarkan pada frekuensi 540-1260 Khz, dan jika pada NDB beroperasi pada saluran frekuensi 190-535 Khz. Beberapa pesawat terbang yang dilengkapi dengan ADF, dapat menerima sinyal frekuensi menengah mulai dari $190 \mathrm{Khz}$ sampai dengan $1750 \mathrm{Khz}$. [6].

\section{Komponen ADF}

1. ADF Receiver, berfungsi untuk mengolah data/signal yang diterima oleh antena.

2. Control Box digunakan untuk menentukan frekuensi yang dituju sesuai dengan rute penerbangan.

3. Antena, berfungsi untuk mendeteksi pergerakan pesawat atau bearing dan untuk mendeteksi sinyal audio. Pesawat Terdiri dari dua antena. 
Dua antena disebut Expired Antena LOOP dan Antena SENSE. ADF Menerima sinyal pada Kedua lingkaran antena dan rasa. Antena loop umum digunakan saat ini adalah antena flat kecil tanpa bagian yang bergerak. Dalam kumparan antena spasi beberapa di berbagai sudut. Antena loop merasakan pengelolaan stasiun dengan kekuatan sinyal dimaksudkan setiap koil tidak dapat menentukan apakah bearing adalah TO atau FROM stasiun. Antena rasa Menyediakan lathing informasi ini.

4. Bearing Indicator, berfungsi untuk menampilkan bearing ke stasiun relatif terhadap hidung pesawat.

\section{Prinsip Kerja ADF}

Dalam suatu penerbangan pilot akan memilih frekuensi radio ADF berdasarkan jalur penerbangan dalam rencana penerbangan yang ditentukan sebelumnya, dan memanfaatkan tombol tuning untuk menyetel frekuensi groundstasiun. Receiver ADF pada pesawat akan menerima sinyal yang diproyeksikan dari stasiun NDB yang ditunjukan oleh jarum (pointer) yang ada pada display indikator. Dengan demikian pilot dapat langsung menentukan arah yang akan dituju melalui arah jarum pada display indikator, dan kesalahan dalam mengambil sudut heading akan bisa dihindari. [6]

\section{Operasional ADF}

\section{Homing}

Bila menggunakan prosedur ini, pilot terbang ke stasiun dengan menjaga jarum bearing indicator pada $0^{\circ}$ bila menggunakan ADF fixed-card.

\section{Bracketing}

Bracketing pada bearing magnetik ADF membutuhkan pilot untuk mengidentifikasi dengan menggunakan bearing indikator dan heading indikator. Setiap kali heading pesawat dan relatif bearing yang sama lebih dari $360^{\circ}$, pilot harus mengurangi $360^{\circ}$ dari angka yang dihasilkan. pilot kemudian mengikuti sisa prosedur bracketing.

\section{Tracking dari Stasiun}

Seorang pilot dapat menggunakan ADF untuk melakukan track dari stasiun dengan menggunakan prinsip-prinsip bracketing arah magnetis.

\section{Posisi Fix by ADF}

Receiver ADF dapat membantu pilot untuk memperbaiki posisi yang tepat dengan menggunakan dua atau lebih stasiun dan proses triangulasi.

\section{METODE PENELITIAN}

Penelitian yang peneliti buat menggunakan metode penelitian metode studi pustaka dan observasi yaitu sebagai berikut: a. Observasi

Peneliti melakukan pengamatan secara langsung mengenai pembelajaran avionik ADF di LAB.

b. Studi Pustaka

Peneliti mencari literatur bacaan serta sumber referensi yang mendukung dan berkaitan dengan topik yang peneliti ambil agar mendapat landasan teoritis yang akurat.

Pengembangan Digitalisasi Media Pembelajaran Avionic untuk Implementasi dalam penelitian ini menggunakan metode Multimedia Development Life Cycle (MDLC) [7] yang terdiri dari 6 tahap. Tahapantahapan dalam MDLC yang tersusun secara sistematis adalah sebagai berikut :

\section{Konsep (Concept)}

Pada tahap konsep, dimulai dengan menentukan tujuan pembuatan digitaliasi media pembelajaran avionic serta menentukan pengguna animasi multimedia tersebut. Pada penelitian ini, tujuan pembuatan animasi multimedia adalah membantu taruna dalam mempelajari avionic.

\section{Perancangan (Desain)}

Tujuan dari tahap perancangan adalah membuat spesifikasi secara terperinci mengenai arsitektur proyek, tampilan dan kebutuhan material proyek, serta gaya. Tahap ini menggunakan storyboard untuk menggambarkan rangkaian cerita atau deskripsi tiap scene sehingga dapat dimengerti oleh pengguna, dengan mencantumkan semua objek multimedia dan tautan ke scene lain.

\section{Pengumpulan Bahan (Material Collecting)}

Material Collecting adalah tahap pengumpulan bahan yang sesuai dengan kebutuhan. Bahan-bahan tersebut antara lain gambar, foto, animasi, video, audio, serta teks baik yang sudah jadi ataupun yang masih perlu dimodifikasi sesuai dengan kebutuhan yang ada. Bahan-bahan tersebut dapat diperoleh secara gratis atau dengan pemesanan kepada pihak lain sesuai dengan rancangan yang telah dibuat pada tahap sebelumnya.

\section{Pembuatan (Assembly)}

Tahap assembly adalah tahap pembuatan keseluruhan bahan multimedia. Aplikasi yang akan dibuat didasarkan pada tahap design, seperti storyboard.

\section{Pengujian (Testing)}

Pengujian dilakukan untuk memastikan bahwa hasil pembuatan animasi multimedia sesuai dengan rencana. Ada dua jenis pengujian yang digunakan, yaitu pengujian alpha dan pengujian beta. 


\section{Distribusi (Distribution)}

Tahap ini adalah tahap terakhir dalam siklus pengembangan multimedia. Pendistribusian dapat dilakukan setelah aplikasi dinyatakan layak pakai. Pada tahap ini, aplikasi akan disimpan dalam suatu media penyimpanan seperti $\mathrm{CD}$, hardisk, server, perangkat mobile atau situs web. Jika media penyimpanan tidak cukup untuk menampung animasi multimedianya, kompresi terhadap animasi multimedia tersebut akan dilakukan. Tahap evaluasi termasuk ke dalam tahap ini. Adanya evaluasi sangat dibutuhkan untuk pengembangan animasi multimedia yang sudah dibuat sebelumnya agar menjadi lebih baik.

\section{HASIL DAN PEMBAHASAN}

\section{Konsep}

Didalam Rancang Bangun Media Pembelajaran Avionic - Automatic Direction Finding System Berbasis Animasi ini terdapat 3 sub video:

i. Introduction

ii. Komponen ADF

iii. Direction Finding System

Dimana masing masing video akan menjelaskan secara detail point point penting dalam Automatic Direction Finding System dalam durasi menit dengan menampilkan multimedia animasi berisi text dan suara untuk penjelasan.

\section{Perancangan}

Didalam Rancang Bangun Media Pembelajaran Avionic - Automatic Direction Finding System Berbasis Animasi ini terdapat 5 jenis tampilan yaitu :

a. Halaman Introduction

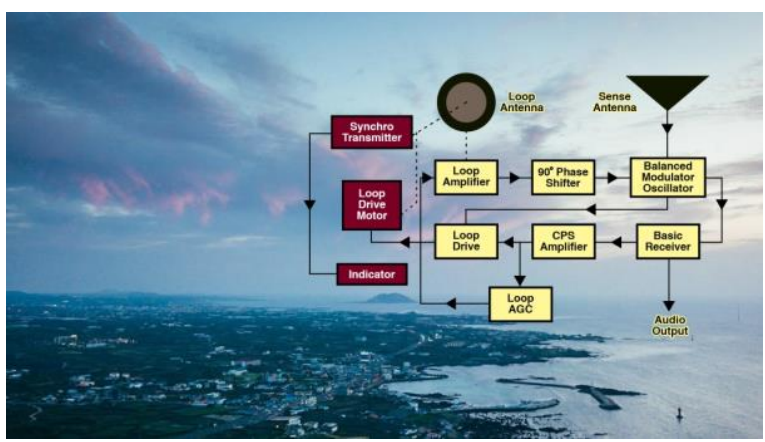

Gambar 1. System ADF b. Tampilan bagian system

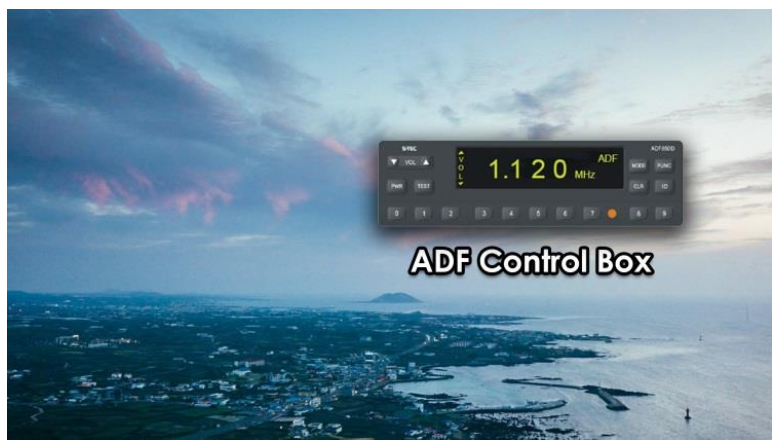

(a)

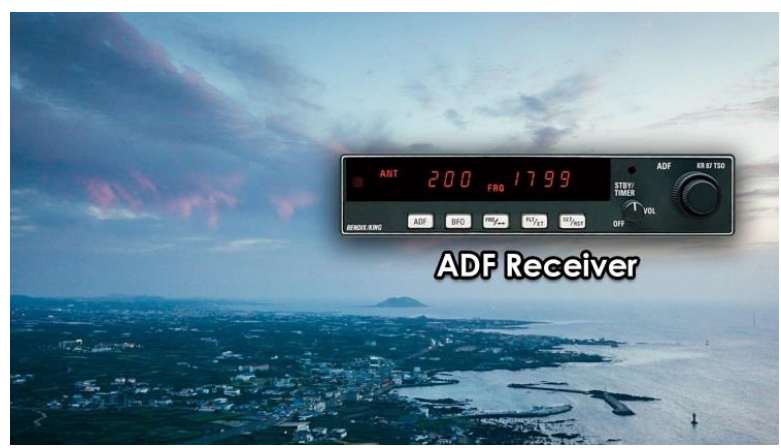

(b)

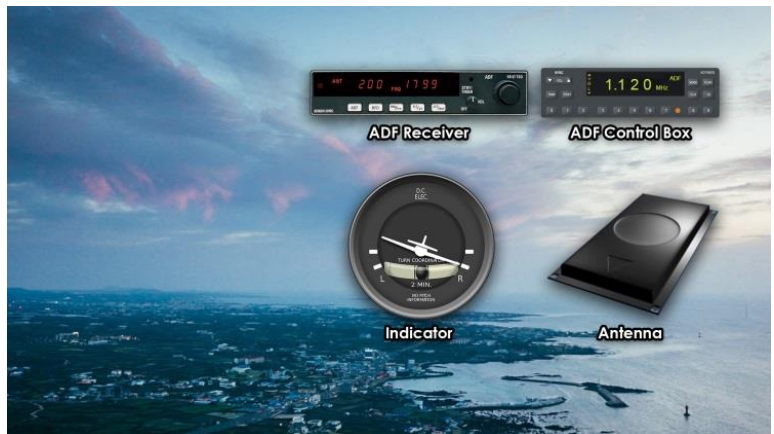

(c)

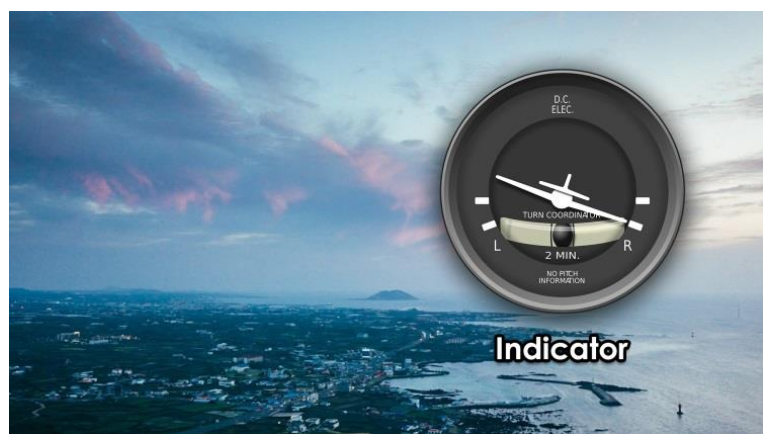

(d)

Gambar 2. (a) (b) (c) (d) Komponen ADF 
c. Tampilan Sense Antenna

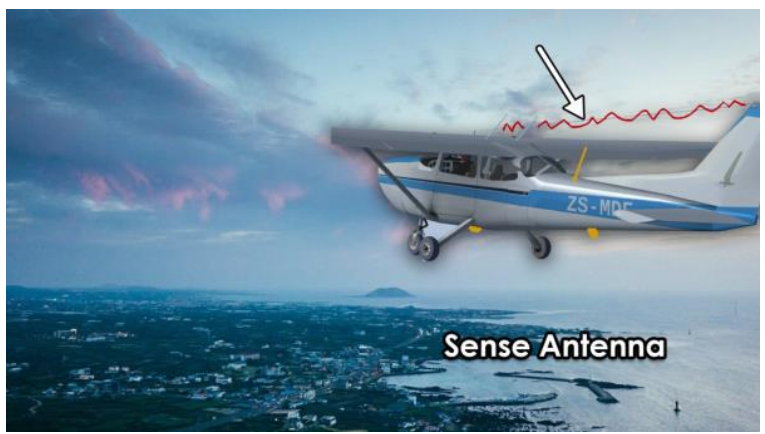

Gambar 3. Tampilan Sense Antenna

\section{d. Komponen Antena}

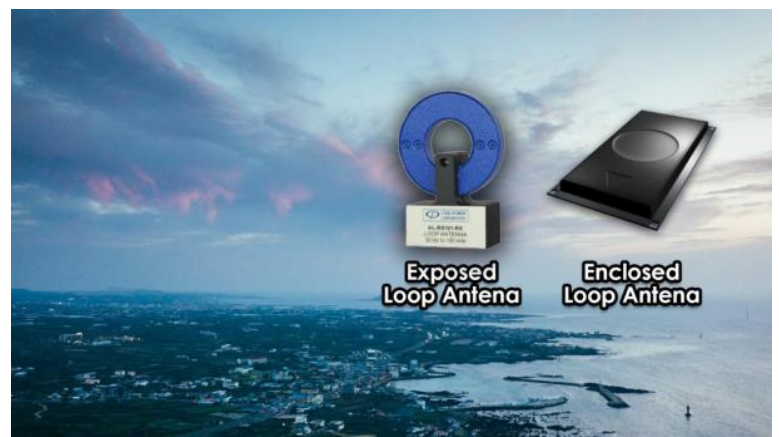

Gambar 4. Tampilan Komponen Antena

e. Tampilan Finding Direction System

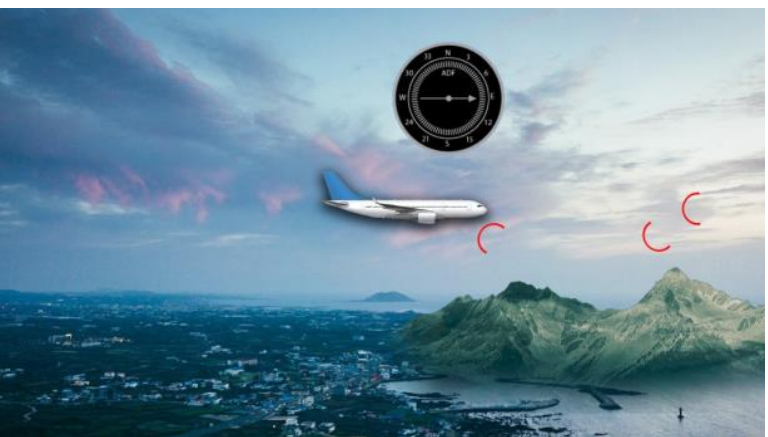

(a)

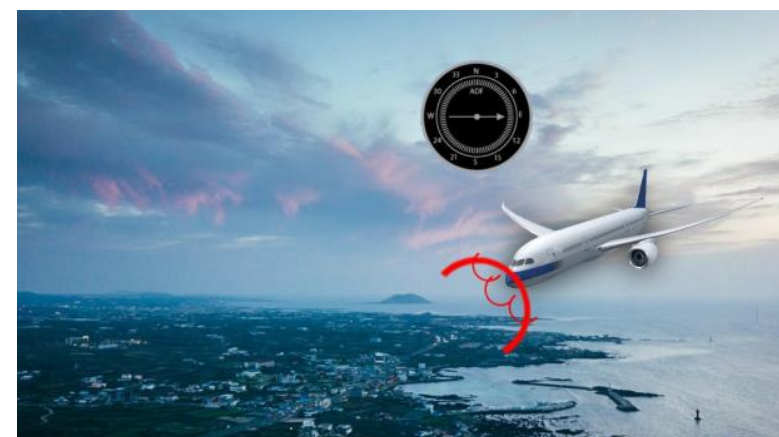

(b)

Gambar 5. (a) (b) Tampilan Finding Direction

\section{Pengumpulan Bahan}

Material yang digunakan untuk menghasilkan media pembelajaran ini dibuat sendiri, membeli ataupun memanfaatkan material yang ada yang terdapat di website-website tertentu. Dalam penyusunan Media Pembelajaran Avionic - Automatic Finding System Berbasis Animasi ini kami mendapatkan material asset animasi yang dibuat dengan aplikasi text to spech balabolka dengan memanfaatkan asset yang ada.

4. Pembuatan

Aplikasi photoshop dan adobe premiere digunakan dalam membangun media pembelajaran ini, untuk tampilan suara menggunakan text to spech dan Balabolka yang disusun sesuai timeline tertentu agar bisa menampilkan multimedia animasi.

\section{Pengujian}

Berikut penjelasan mengenai hasil testing Rancang Bangun Media Pembelajaran Avionic Automatic Direction Finding System Berbasis Animasi yang telah dibuat :

a. Media Pembelajaran Avionic - Automatic Direction Finding System Berbasis Animasi berbentuk landscape yang sudah disesuaikan dengan resolusi yang dapat di upload kedalam Youtube sehingga tidak terlalu berat jika dijalankan nanti di android.

b. Setelah kita menekan play maka video akan menampilkan Media Pembelajaran Avionic Automatic Direction Finding System Berbasis Animasi.

Dari hasil pengujian yang telah dilakukan, dapat dilihat bahwa Media Pembelajaran Avionic - Radio Theory I Berbasis Animasi yang telah dibuat dapat berjalan dengan baik dengan video berdurasi sekitar 10 menit.

\section{Distribus}

Video Avionic - Automatic Direction Finding System Berbasis Animasi sebagai bentuk digitalisasi media pembelajaran sudah selesai dibuat dan digunakan dilingkungan internal ATKP Medan.

\section{KESIMPULAN}

Untuk menghasilkan sebuah rancang bangun media pembelajaran Avionic - Automatic Direction Finding System memerlukan 5 jenis tampilan yaitu halaman introduction, halaman komponen ADF, Sense Antenna, Komponen Antena, dan Direction Finding System. Media pembelajaran yang dihasilkan berdurasi sekitar 10 menit, yang dapat dimanfaatkan untuk taruna sebagai bahan pembelajaran Automatic Direction Finding System.

Adapun saran yang diberikan untuk selanjutnya adalah dengan menambahkan studi kasus atau soal latihan kedalam konten pembelajaran. 


\section{DAFTAR PUSTAKA}

[1] I. Idris and Y. Delvika, "Analisis perancangan sistem informasi terintegrasi di lingkungan perguruan tinggi swasta di medan," J. Teknovasi J. Tek. dan Inov., vol. 1, no. 2, pp. 15-26, 2014.

[2] I. Idris and H. N. Nazaruddin, "Mapping function and alignment of Information and Communication Technology (ICT) for private higher education," $3 r d$ Int. Conf. Mulitidisciplinary Res. 2014 (ICMR 2014) Medan, vol. 1, no. October, 2014.

[3] Wikipedia, “Avionics," Wikipedia, 2018. [Online]. Available: https://en.wikipedia.org/wiki/Avionics.

[Accessed: 17-Aug-2019].

[4] Wikipedia, "Radio direction finder," Wikipedia, 2019. [Online]. Available: https://en.wikipedia.org/wiki/Radio_direction_fin der. [Accessed: 18-Jul-2019].

[5] Thai Technics.Com, "Automatic Direction Finder," Thai Technics.Com, 2010. [Online]. Available:

http://www.thaitechnics.com/nav/adf.html. [Accessed: 18-Aug-2019].

[6] Federal Aviation Administration, Aviation Maintenance Handbook-Powerplant Volume 2, vol. 2. 2012.

[7] I. M. Faizal, N. Nurhasanah, and E. Rahmawati, "Digitalisasi Permainan Tradisional Galah Melalui Media Game," vol. 1, no. 1, pp. 17-21, 2019. 